UDC 691:620.3

Author: MASSALIMOV Ismail Alexandrovich, Doctor of Engineering, Bashkir State University (BashSU), Scientific and Research Technological Institute of Herbicides of the Academy of Sciences of the Republic of Bashkortostan (SBI «SRTIH AS RB»); Mushnikov str., 13/2-75, Ufa, 450039; ismail_mass@mail.ru;

Author: CHUYKIN Aleksandr Evgenievich, Candidate of Engineering Sciences, Docent, Ufa State Petroleum Technological University (USPTU), the Department «Building Constructions»; Kosmonavtov str., 1, Ufa, 450062, Russian Federation; an2100@yandex.ru;

Author: MASSALIMOV Burhan Ismailovich, Graduate student, Physics Institute. P.N. Lebedev, Russian Academy of Sciences; Leninsky Prospect, 63, Moscow, 119991; burhan@mephist.ru;

Author: URAKAEV Farit Hisamutdinovich, Doctor of Chemistry, Senior Researcher, V.S. Sobolev Institute of Geology and Mineralogy of the Russian Academy Science; Koptyuga str. 3, Novosibirsk, 630090; urakaev@igm.nsc.ru;

Author: URALBEKOV Bolat Muratovich, Ph.D. in Chemistry, Head of the department, Al-Farabi Kazakh National University; Al-Farabi Avenue 71, Almaty (Kazakhstan), 050040;

bulat.ural@gmail.com;

Author: BURKITBAEV Muhambetkali Myrzabaevich, Doctor of Chemistry, Vice Rector, Al-Farabi Kazakh National University; Al-Farabi Avenue 71, Almaty (Kazakhstan), 050040;

mukhambetkali.Burkitbayev@kaznu.kz

\title{
IMPROVEMENT OF OPERATIONAL PROPERTIES OF SHELL LIMESTONE BUILDING MATERIALS BY POLYSULFIDE SOLUTION IMPREGNATION
}

\section{Extended Abstract:}

The data of studies on the effectiveness of impregnation with polysulfide solutions of shell limestone used as facing and wall material, as well as for the manufacture of road products are presented. Modification of the limestone with the impregnating composition "Akvastat» created by the authors which is sulfur-containing water-based solution of calcium polysulfide containing alcohols and surfactants, can significantly reduce water absorption and increase durability of limestone.

Impregnating composition on the basis of calcium polysulfide possesses density of $1.22-1.24 \mathrm{~g} / \mathrm{cm}^{3}$, the infiltrant penetrates into the pore structure of limestone to a depth of $4 \mathrm{~cm}$ or more, depending on the density and structure of the sample. While the material is drying, sulfur nanoparticles are crystallized from the polysulfide solution in its pores. They partially fill pore space and form protective durable insoluble hydrophobic coating that impedes the penetration of 
water into the pores of the limestone, but preserves its vapor permeability, which is important for wall and decoration materials.

The evaluation of protective coatings was performed with laser particle size analyzer, scanning probe microscope and a diffractometer. It showed that the average size of the particles forming the protective coating is in the range of 20$25 \mathrm{~nm}$, the particles shape is spherical, the particles are elemental sulfur with orthorhombic structure of the crystal lattice.

The processing of shell limestone with calcium polysulphide solution provides formation of coating based on nanosized sulfur on the surface of stone pores. The coating partially fills the pore space and, as it is hydrophobic, reduces the water absorption of the samples by a factor of 5-8, increases their average density by $22-27 \%$, strength in $1,2-1,3$ times, the softening factor by $6-19 \%$, that makes possible to predict the increase of the durability of building materials based on shell limestone to 1.5-2 times or more.

Impregnation of the wall, facing and road construction materials and limestone products with polysulfide composition "Akvastat» allows improving their operational properties, increasing resistance to weathering, expanding their area of application in the climatic conditions of Central Russia.

Key words: shell limestone, sulfur, nanoparicle, impregnation, hydrophobization, polysulphide.

DOI: dx.doi.org/10.15828/2075-8545-2017-9-3-66-80

MACHINE-READABLE INFORMATION ON CC-LICENSES (HTML-CODE) IN METADATA OF THE PAPER

$<$ a rel="license" href="http://creativecommons.org/licenses/by/4.0/" $><$ img alt="Creative Commons License" style="borderwidth:0" src="https://i.creativecommons.org/l/by/4.0/88x31.png" / $></ \mathrm{a}><$ br $/><$ span xmlns:dct="http://purl.org/dc/ terms $/$ " property="dct:title" $>$ Improvement of operational properties of shell limestone building materials by polysulfide solution impregnation $</$ span $>$ by $<$ a xmlns:cc="http: $/ /$ creativecommons.org/ns\#" href $=$ "Nanotehnologii v stroitel'stve $=$ Nanotechnologies in Construction. 2017, Vol. 9, no. 3, pp. 66-80. DOI: dx.doi. org/10.15828/2075-8545-2017-9-3-66-80" property="cc:attributionName" rel="cc:attributionURL"> Massalimov I.A., Chuykin A.E., Massalimov B.I., Urakaev F.H., Uralbekov B.M., Burkitbaev M.M. </a $>$ is licensed under a <a rel="license" href="http://creativecommons.org/licenses/ by $/ 4.0 /$ " $>$ Creative Commons Attribution 4.0 International License $</ \mathrm{a}>$. $<$ br $/>$ Based on a work at $<$ a xmlns:dct="http:// purl.org/dc/terms/" href=" http://nanobuild.ru/en_EN/nanobuild-3-2017/" rel="dct:source"> http://nanobuild.ru/ en_EN/nanobuild-3-2017/</a $>$. $<$ br $/>$ Permissions beyond the scope of this license may be available at $<$ a xmlns:cc="http:// creativecommons.org/ns\#" href="ismail_mass@mail.ru" rel="cc:morePermissions" >ismail_mass@mail.ru</a> .

\section{References:}

1. Dvorkin L.I., Dvorkin O.L. Stroitel'noe materialovedenie [Building Material Science]. Moscow, Infra - Inzheneriya. 2013. 832 p. (In Russian). 
2. Ambartsumyan N.V. Stroitel'nye gornye porody dlya proizvodstva stenovykh i oblitsovochnykh materialov [Construction of the rock for the production of wall and facing materials]. Moscow, MGI. 1982. 282 p. (In Russian).

3. Sementovskii Yu.V. Kamni oblitsovochnye: Spravochnik [Facing stones: Hand-Book]. Nauchnyi redaktor A.S. Fil'ko; Ministerstvo prirodnykh resursov RF. Moscow, Geoinformmark. 1998. 25 p. (In Russian).

4. Sementovskii Yu.V. Izvestnyak: Spravochnik [Limestone: Hand-Book]. Nauchnyi redaktor A.S. Fil'ko; Ministerstvo prirodnykh resursov RF. Moscow, Geoinformmark. 1999. 19 p. (In Russian).

5. Gornaya entsiklopediya [The mountain encyclopedia]. Glavnyi redaktor E.A. Kozlovskii; Redaktsionnaya kollegiya: M.I. Agoshkov, N.K. Baibakov, A.S. Boldyrev i drugie. Moscow, Sovetskaya entsiklopediya. 1985. Vol. 2. 575 p. (In Russian).

6. Bakka N.T. Oblitsovochnyi kamen'. Geologo-promyshlennaya i tekhnologicheskaya otsenka mestorozhdenii: Spravochnik [Facing stone. Geological and industrial and technological appraisal of fields: Hand-Book]. Moscow, Nedra. 1992. 303 p. (In Russian).

7. Prirodnye oblitsovochnye kamni Kazakhstana: spravochnik [Natural facing stones of Kazakhstan: reference book]. Pod redaktsiei A.A. Abdullina, Kh.A. Bespaeva, E.S. Votsalevskogo, S.Zh. Daukeeva, L.A. Miroshnichenko. Almaty, Informatsionno-analiticheskii tsentr geologii i mineral'nykh resursov RK. 2000. Vol. 1. 181 p. (In Russian).

8. Chukhlanov V.Yu., Alekseenko A.N. Gidrofobiziruyushchaya zhidkost' dlya betonnykh i zhelezobetonnykh konstruktsii [Repellent liquid for concrete and reinforced concrete structures]. Stroitel'nye materialy. 2003. No. 12, pp. 38-39. (In Russian).

9. Loganina V.I., Orentlikher L.P. Stoikost' zashchitno-dekorativnykh pokrytii naruzhnykh sten zdanii [Resistance of protective-decorative coatings of external walls of buildings]. Moscow, Izdatel'stvo Assotsiatsiya stroitel'nykh vuzov. 2000. 104 p. (In Russian).

10. Reibman A.I. Zashchitnye lakokrasochnye pokrytiya [Protective paint and varnish coatings]. Leningrad, Khimiya. 1982. 320 p. (In Russian)

11. Massalimov I.A., Volgushev A.N., Chuikin A.E., Khusainov A.N., Mustafin A.G. Long-term protection of building materials coatings based on nanoscale sulfur. Nanotehnologii v stroitel'stve $=$ Nanotechnologies in Construction. 2010. No. 1, pp. 45-58. Available at: http://www.nanobuild.ru/ru_RU/journal/Nanobuild_1_2010_RUS.pdf (date of access 24.04.2017). (In Russian).

12. Yanahmetov M.R., Chuykin A.E., Massalimov I.A. Modification of the pore structure of cement concrete impregnation with sulfur-containing solutions. Nanotehnologii v stroitel'stve $=$ Nanotechnologies in Construction. 2015. Vol. 7. No. 1, pp. 63-72. Available at: http://nanobuild.ru/ru_RU/journal/Nanobuild-1-2015/63-72.pdf (date of access 24.04.2017). (In Russian).

13. Massalimov I.A., Yanahmetov M.R., Chuykin A.E. Strength and durability of concrete, modified impregnating composition based on sulfur. Nanotehnologii v stroitel'stve = Nanotechnologies in Construction. 2015. Vol. 7. No. 3, pp. 61-75. Available at: http://www. nanobuild.ru/en_EN/journal/Nanobuild-3-2015/61-75.pdf (date of access 24.04.2017). (In Russian). 
14. Massalimov I.A., Mustafin A.G., Chuikin A.E., Volgushev A.N., Massalimov B.I., Khusainov A.N. The hardening and increasing of the water resistance of concrete coatings based on nanoscale sulfur. Nanotehnologii v stroitel'stve $=$ Nanotechnologies in Construction. 2010. No. 2, pp. 54-61. Available at: http://www.nanobuild.ru/ru_RU/journal/Nanobuild_2_2010_RUS.pdf (date of access 24.04.2017). (In Russian).

15. Massalimov I.A., Yanakhmetov M.R., Chuykin A.E., Mustafin A.G. Protection of Building Constructions with Sulfur Impregnating Solution. Study of Civil Engineering and Architecture (SCEA). June 2013. Vol. 2. Issue 2. pp. 19-24.

16. Yanakhmetov M.R., Massalimov I.A., Chuykin A.E., Khusainov A.N., Mustafin A.G. Transformatsiya molekul polisul'fidov v nanorazmernye chastitsy sery v poristykh neorganicheskikh sistemakh [Transformation of polysulfide molecules into nanosized sulfur particles in porous inorganic systems]. Vestnik Bashkirskogo Universiteta. 2013. Vol. 18. No. 3, pp. 691-693. (In Russian).

17. Patent RF 2416589. Sostav dlya obrabotki stroitel'nykh materialov i sposob ikh obrabotki [Composition for treatment of construction materials and method to process them]. Massalimov I.A., Babkov V.V., Mustafin A.G. Declared 23.09.2009. Published 20.04.2011. Bulletin No. 11. (In Russian).

18. Eurasian patent 024383. Sposob obrabotki stroitel'nykh materialov polisul'fidnymi rastvorami [A method to treat building materials with polysulfide solutions]. Massalimov I.A., Yanahmetov M.R., Chuykin A.E., Khusainov A.N., Mustafin A.G. Declared 26.03.2014. Published 30.09.2016. Bulletin No. 9. (In Russian).

19. GOST 9479-2011. Rough blocks for manufacture of facing, architectural and building, memorial and other products. Specifications. (In Russian).

20. GOST 30629-2011. Facing materials and products made of natural stone. Test methods. (In Russian).

\section{DeAr Colleagues!}

THE REFERENCE TO THIS PAPER HAS THE FOLLOWING CITATION FORMAT:

Massalimov I.A., Chuykin A.E., Massalimov B.I., Urakaev F.H., Uralbekov B.M., Burkitbaev M.M. Improvement of operational properties of shell limestone building materials by polysulfide solution impregnation. Nanotehnologii v stroitel'stve = Nanotechnologies in Construction. 2017, Vol. 9, no. 3, pp. 66-80. DOI: dx.doi. org/10.15828/2075-8545-2017-9-3-66-80. (In Russian).

Contact information

\section{Massalimov Ismail Alexandrovich} ismail_mass@mail.ru 
уДК 691:620.3

Автор: МАССАЛИМОВ Исмаил Александрович, д-р техн. наук, проф., Башкирский государственный университет (ФГБОУ ВО БашГУ); зав. лабораторией, Научно-исследовательский технологический институт гербицидов Академии наук Республики Башкортостан (ГБУ «НИТИГ АН РБ»); ул. Мушникова, 13/2-75, г. Уфа, 450039; ismail_mass@mail.ru;

Автор: ЧУЙкИН Александр Евгеньевич, канд. техн. наук, доцент каф. «Строительные конструкции», Уфимский государственный нефтяной технический университет (УГНТУ); ул. Космонавтов, 1, г. Уфа, 450062, an2100@уandex.ru;

Автор: МАССАЛИМОВ Бурхан Исмаилович, аспирант, Физический институт им. П.Н. Лебедева РАН; Ленинский проспект, д. 63, Москва, 119991; burhan@mephist.ru;

Автор: УРАКАЕВ Фарит Хисамутдинович, д-р хим. наук, вед. научн. сотр., Институт геологии и минералогии имени В.С. Соболева СО РАН; проспект Академика Коптюга, 3, Новосибирск, 630090,urakaev@igm.nsc.ru;

Автор: УРАЛБЕКОВ Болат Муратович, канд. хим. наук, зав. кафедрой, Казахский национальный университет им. аль-Фараби; проспект аль-Фараби, 71, Казахстан, Алматы, 050040;

bulat.ural@gmail.com;

Автор: БУРКИТБАЕВ Мухамбеткали Мырзабаевич, д-р хим. наук, проректор, Казахский национальный университет им. аль-Фараби; проспект аль-Фараби, 71, Казахстан, Алматы, 050040; mukhambetkali.Burkitbayev@kaznu.kz

\section{УЛУЧШЕНИЕ ЭКСПЛУАТАЦИОННЫХ СВОЙСТВ СТРОИТЕЛЬНЫХ МАТЕРИАЛОВ ИЗ ИЗВЕСТНЯКА-РАКУШЕЧНИКА ПРОПИТКОЙ ПОЛИСУЛЬФИДНЫМИ РАСТВОРАМИ}

АННОТАЦИЯ К СТАТЬЕ (АВТОРСКОЕ РЕЗЮМЕ, РЕФЕРАТ):

Представлены данные исследований по эффективности пропитки полисульфидными растворами известняка-ракушечника, используемого в качестве облицовочного и стенового материала, а также для изготовления дорожных изделий. Модифицирование известняка-ракушечника разработанной нами пропиточной композицией «Аквастат» - водным серосодержащим раствором на основе полисульфида кальция, содержащим спирты и ПАВ - позволяет существенно снизить их водопоглощение и повысить долговечность.

Пропиточный состав на основе полисульфида кальция имеет плотность

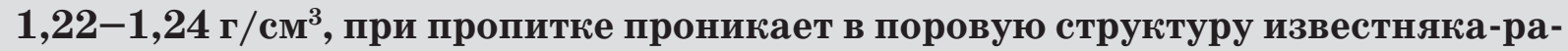
кушечника на глубину до 4 см и более, в зависимости от плотности и структуры образца. При высыхании материала в его порах из полисульфидного раствора выкристаллизовываются наночастицы серы, частично заполняющие 
поровое пространство и формирующие защитное долговечное нерастворимое гидрофобное покрытие, затрудняющее проникновение воды в поры ракушечника, но сохраняющее его паропроницаемость, что важно для стеновых и облицовочных материалов.

Оценка характеристик защитного покрытия с помощью лазерного анализатора размеров частиц, зондового микроскопа и дифрактометра показала, что средний размер частиц, образующих защитное покрытие, находится в интервале 20-25 нм, частицы имеют сферически симметричную форму, частицы являются элементной серой с орторомбической структурой кристаллической решетки.

Обработка известняка-ракушечника раствором полисульфида кальция обеспечивает образование на поверхности пор камня покрытия на основе наноразмерной серы, которое частично заполняет поровое пространство и, обладая гидрофобностью, уменьшает водопоглощение образцов в 5-8 раз, повышает их среднюю плотность на 22-27\%, прочность в 1,2-1,3 раза, коэффициент размягчения - на 6-19\%, что позволяет прогнозировать повышение долговечности строительных материалов на основе известняка-ракушечника до 1,5-2 раз и более.

Пропитка стеновых, облицовочных и дорожных строительных материалов и изделий из известняка-ракушечника полисульфидной композицией «Аквастат» позволяет улучшить их эксплуатационные свойства, повысить стойкость к атмосферным воздействиям, расширить их область применения в климатических условиях средней полосы России.

Ключевые слова: известняк-ракушечник, сера, наночастица, пропитка, гидрофобизация, полисульфид.

DOI: dx.doi.org/10.15828/2075-8545-2017-9-3-66-80

МАшИНОЧИТАЕМАЯ ИНФОРМАЦИЯ О СС-ЛИЦЕНЗИИ В МЕТАДАННЫХ СТАТЬИ (HTML-КОд):

$<$ a rel="license" href="http://creativecommons.org/licenses/by/4.0/" ><img alt="Лицензия Creative Commons" style="borderwidth:0" src="https://i.creativecommons.org/l/by/4.0/88x31.png" / $></ \mathrm{a}><$ br $/>$ Произведение «<span xmlns:dct="http://purl org/dc/terms/" href="http://purl.org/dc/dcmitype/Text" property="dct:title" rel="dct:type">Улучшение эксплуатационных свойств строительных материалов из известняка-ракушечника пропиткой полисульфидными растворами</span $>$ » созданное автором по имени $<\mathrm{a}$ xmlns:cc="http://creativecommons.org/ns\#" href="Нанотехнологии в строительстве. - 2017. - Том 9, № 3. - C. $66-80$. - DOI: dx.doi.org/10.15828/2075-8545-2017-9-3-66-80" property="cc:attributionName" rel="cc:attributionUR L"> Массалимов И.А., Чуйкин А.Е., Массалимов Б.И., Уракаев Ф.Х., Уралбеков Б.М., Буркитбаев М.М. </а >, публикуется на условиях $<$ a rel="license" href="http://creativecommons.org/licenses/by/4.0/">лицензии Creative Commons "Attribution" ( «Атрибуция») 4.0 Всемирная $<$ a $>$. $<$ br /> Основано на произведении с $<$ a xmlns:dct="http://purl.org/dc/terms/" href="http:// nanobuild.ru/ru_RU/nanobuild-3-2017/" rel="dct:source">http://nanobuild.ru/ru_RU/nanobuild-3-2017/</a $>$. $<$ br $/>$ Paspeweния, выходящие за рамки данной лицензии, могут быть доступны на странице $<\mathrm{a}$ xmlns:cc="http://creativecommons.org/ns\#" href="ismail_mass@mail.ru"rel="cc:morePermissions">ismail_mass@mail.ru</a>. 
войства, структурные особенности и состав осадочной горной породы - известняка-ракушечника - обусловили его широкое применение во многих областях народного хозяйства. Благодаря декоративным качествам, легкости обработки, экологичности и значениям теплопроводности, паро- и воздухопроницаемости, превосходящим аналогичные характеристики для керамического кирпича, ракушечник традиционно используется в качестве стенового и отделочного материала в индивидуальном жилищном строительстве $[1,2]$.

В строительстве известняк-ракушечник в большом объеме применяется в виде бутового камня, штучного (пильного) стенового камня и перегородочных блоков, фасадной и половой облицовочной плиты, плитки для внутренней отделки, тротуарной плитки, бордюрных камней, элементов лестниц, заборов, декоративных фасадных элементов, объектов ландшафтного дизайна, малых архитектурных форм, а также щебня и песка $[1,3]$.

В СССР известняк-ракушечник добывался в значительных объемах. В 1986 году разрабатывалось 149 месторождений, было получено 9585 тыс. м $^{3}$ камня. Большие залежи известняка-ракушечника находятся и разрабатываются на Крымском полуострове, в регионах Краснодарского края, в Дагестане, в Красноярском крае, Белгородской, Тульской, Московской, Вологодской, Воронежской областях России, окрестностях Санкт-Петербурга, в Азербайджане, Молдове, Одесской и Донецкой областях Украины, в Киргизии и Казахстане [3, 4, 6].

В Казахстане разведано около 100 месторождений известняка-ракушечника. В большом объеме его добыча ведется на Жетыбайском, Бейнеуском, Карамандыбасском, Бешкудукском, Каракусском, Састюбинском месторождениях, в районе Форта-Шевченко, Сарташа, местности Кызылкум, села Курык Мунайлинского района и на ряде других карьеров. Значительные разведанные запасы известняка-ракушечника в Казахстане (более 180 млн. т) и относительно низкая себестоимость добычи камня (700-1100 руб/м³) делают его использование в строительной отрасли перспективным [7].

Структуру известняка-ракушечника как зоогенной породы осадочного происхождения формирует смесь карбоната кальция с различны- 
ми примесями, на основе раковин и раковинного детрита, скрепленных кальцитовым цементом [5]. Структуры известняков существенно отличаются для разных месторождений России и Казахстана (см. рис. 1).

Несмотря на широкое применение известняка-ракушечника в строительстве, необходимо отметить некоторые его недостатки, которые могут снижать эксплуатационные характеристики и долговечность строительных материалов. Известняк-ракушечник гигроскопичен, характеризуется большим объемом пористости, равной 22-50\%, постепенно растворяется в воде, интенсивность растворения повышается при воздействии на камень подземных вод и атмосферных осадков, насыщенных кислыми соединениями, что предопределяет его сравнительно невысокую морозостойкость (марка по морозостойкости F15-F35) и снижение прочности при насыщении водой, величина коэффициента размягчения составляет 0,6-0,9. Кроме того, известняк-ракушечник из некоторых месторождений может подвергаться действию грибков. Высокоразвитая поровая структура и гигроскопичность этого материала способствуют развитию в поровом пространстве плесневых грибов и повреждению материала. Таким образом, актуальными являются вопросы защиты строительных материалов из известняка-ракушечника от увлажнения и повышения их долговечности.

С целью снижения водопоглощения пористых строительных материалов, в том числе известняка-ракушечника, в настоящее время ис-

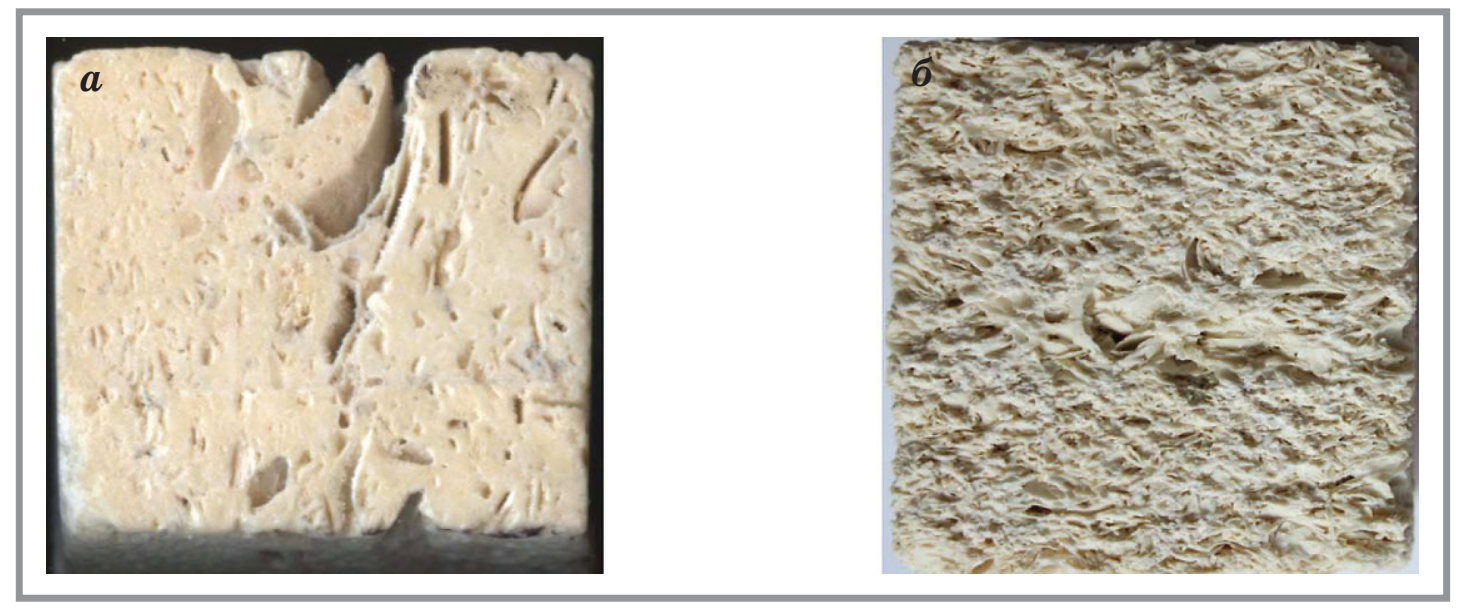

Рис. 1. Структура образцов известняка-ракушечника:

а - Россия (Бурлацкое месторождение);

б - Казахстан (Жетыбайское месторождение) 
пользуются гидрофобизаторы и защитные покрытия на органической и кремнийорганической основе. Покрытия образуют пленку на поверхности материала, уменьшая количество воды, проникающей в поры. Известными недостатками названных покрытий являются ускоренное разрушение в условиях атмосферных воздействий и относительно высокая стоимость защитных составов и гидрофобизаторов $[8,9,10]$.

Одним из наиболее простых и технологичных способов решения задачи улучшения эксплуатационных свойств и повышения долговечности стеновых, облицовочных и дорожных строительных материалов и изделий, в том числе из известняка-ракушечника, может быть их пропитка полисульфидными растворами, обеспечивающая глубокое проникновение пропиточного состава, частичное заполнение пор материала гидрофобной твердой фазой (серой), уменьшение пористости и водопоглощения, повышение его плотности и морозостойкости [11-15].

Пропиточный состав на основе полисульфида кальция - «Аква-

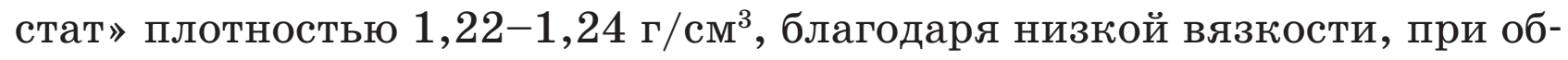
работке проникает в поровую структуру известняка-ракушечника на глубину 2-4 см и более и при последующем высыхании материала образует в его порах долговечное нерастворимое неорганическое защитное покрытие в виде гидрофобных наночастиц серы [16], которые не вымываются водой, растворителями или солевыми растворами $[17,18]$. Характеристики защитного покрытия (размеры частиц и их форма) были оценены с помощью лазерного анализатора размеров частиц Shimadzu Wing SALD 7101 и зондового микроскопа Solver PRO-M, а фазовый анализ проведен на дифрактометре BRUKER D2 PHASER.

Для измерения размеров частиц, выкристаллизовывающихся из полисульфидного раствора на этапе сушки и формирующих защитное покрытие в поровой структуре известняка-ракушечника, они были выделены из порового пространства материала. Для этого пропитанный образец известняка-ракушечника был высушен и растворен в растворе соляной кислоты. Высокодисперсный порошок желтого цвета, выпавший в осадок, был промыт дистиллированной водой и высушен. Определенные с помощью лазерного анализатора дифференциальное и интегральное распределения по размерам частиц осадка (рис. 2а) показали, что средний размер частиц составляет 20 нм. Распределение по размерам частиц, выделенных химическим осаждением непосредственно из раствора полисульфида кальция, и частиц, выделенных из порового про- 

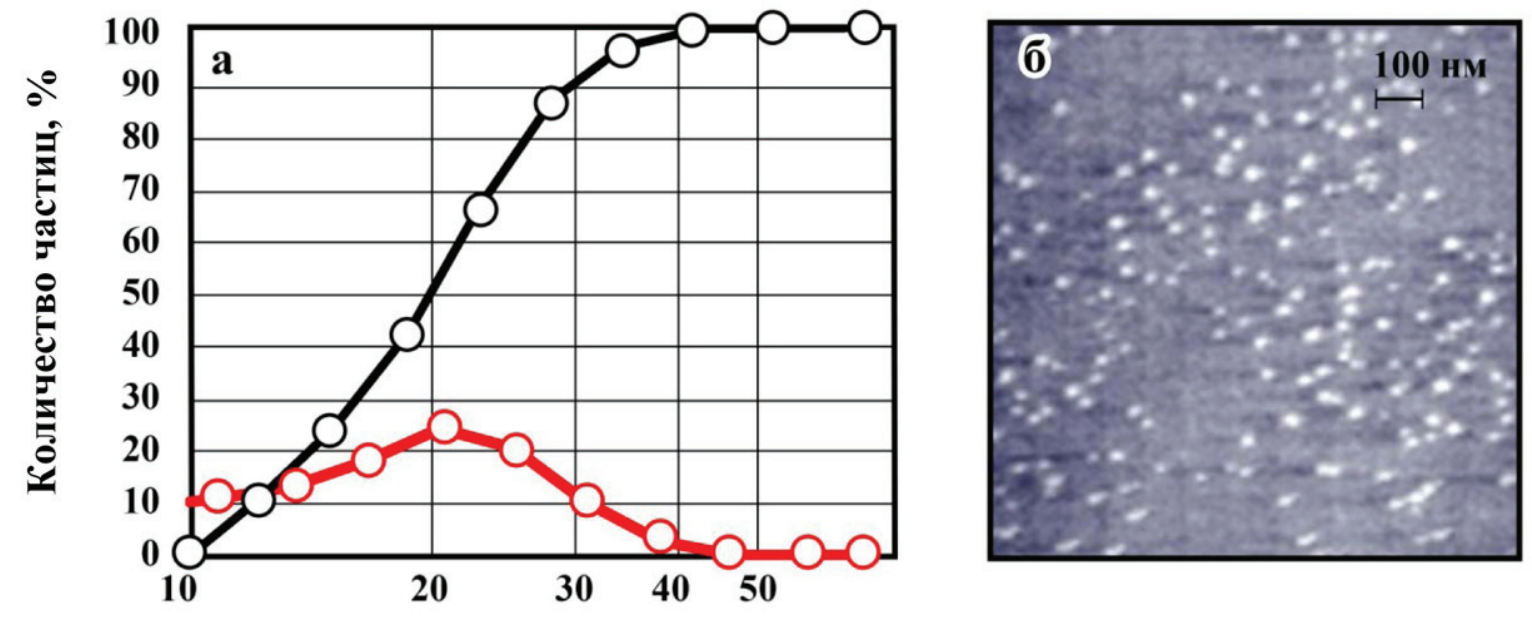

Размеры частиц, нм

Рuc. 2. Интегральное и дифференциальное распределение частиц серы, выделенных из порового пространства известняка-ракушечника, пропитанного полисульфидным раствором (а), и изображение частиц серы, полученное с помощью зондового микроскопа (б)

странства известняка-ракушечника, пропитанного полисульфидным раствором, показало их совпадение. Измерения, проведенные на зондовом микроскопе, также показали значения среднего размера частиц в интервале 20-25 нм, кроме того, установлена их сферически симметричная форма (см. рис. 2б). Химический и рентгеновский дифракционный анализы осадка показали, что частицы являются элементной серой с орторомбической структурой кристаллической решетки (рис. 3).

Исследования по влиянию пропитки полисульфидным раствором на физико-механические свойства известняка-ракушечника, удовлетворяющего требованиям ГОСТ 9479-2011 [19], месторождения Бейнеу (Казахстан) проводились на образцах с водопоглощением по массе 25$28 \%$, средней плотностью 1,19-1,22 г/см ${ }^{3}$, средним пределом прочности при сжатии 2,52 МПа. Пропитка полисульфидным раствором образцовкубов с размером ребра 50 мм осуществлялась полным погружением в ванну в течение 1, 4 и 24 часов при нормальных условиях, а также кистеванием. Водопоглощение по массе, средняя плотность, предел прочности при сжатии и снижение прочности известняка-ракушечника в водонасыщенном состоянии контрольных (необработанных) и пропитанных образцов определялись по методике ГОСТ 30629-2011 [20]. 


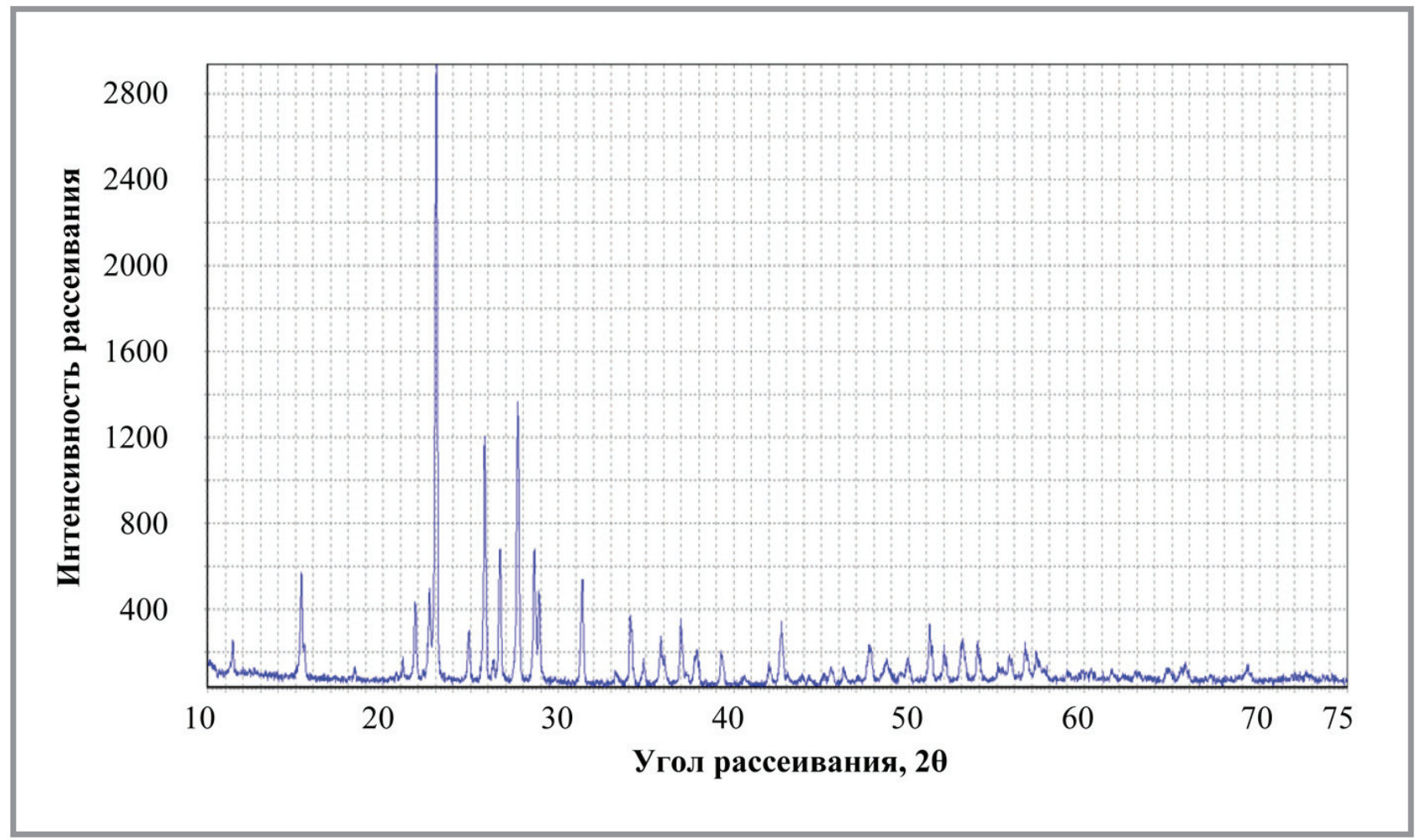

Рис. 3. Рентгенограмма наночастиц серы, выделенных из порового пространства известняка-ракушечника, пропитанного полисульфидным раствором

Результаты определения водопоглощения по массе для образцов известняка-ракушечника, обработанных полисульфидным раствором, приведены на рис. 4. Среднее значение водопоглощения по массе образцов, пропитанных в течение 1 часа, по сравнению с контрольными (непропитанными), снижается на $81 \%$; для образцов, пропитанных в течение 4 часов, снижение составляет $88 \%$.

Сократить сроки пропитки и повысить технологичность обработки строительных материалов из известняка-ракушечника позволяет их поверхностная пропитка кистеванием или с помощью пульверизатора, которая может быть выполнена после окончания строительно-монтажных или отделочных работ. В этом случае пропитка образцов приводит к снижению водопоглощения по массе на 77\% по сравнению с контрольными образцами (рис. 4).

На рис. 5 приведены данные по влиянию режима пропитки полисульфидным раствором на среднюю плотность, прочность при сжатии и коэффициент размягчения образцов известняка-ракушечника. 


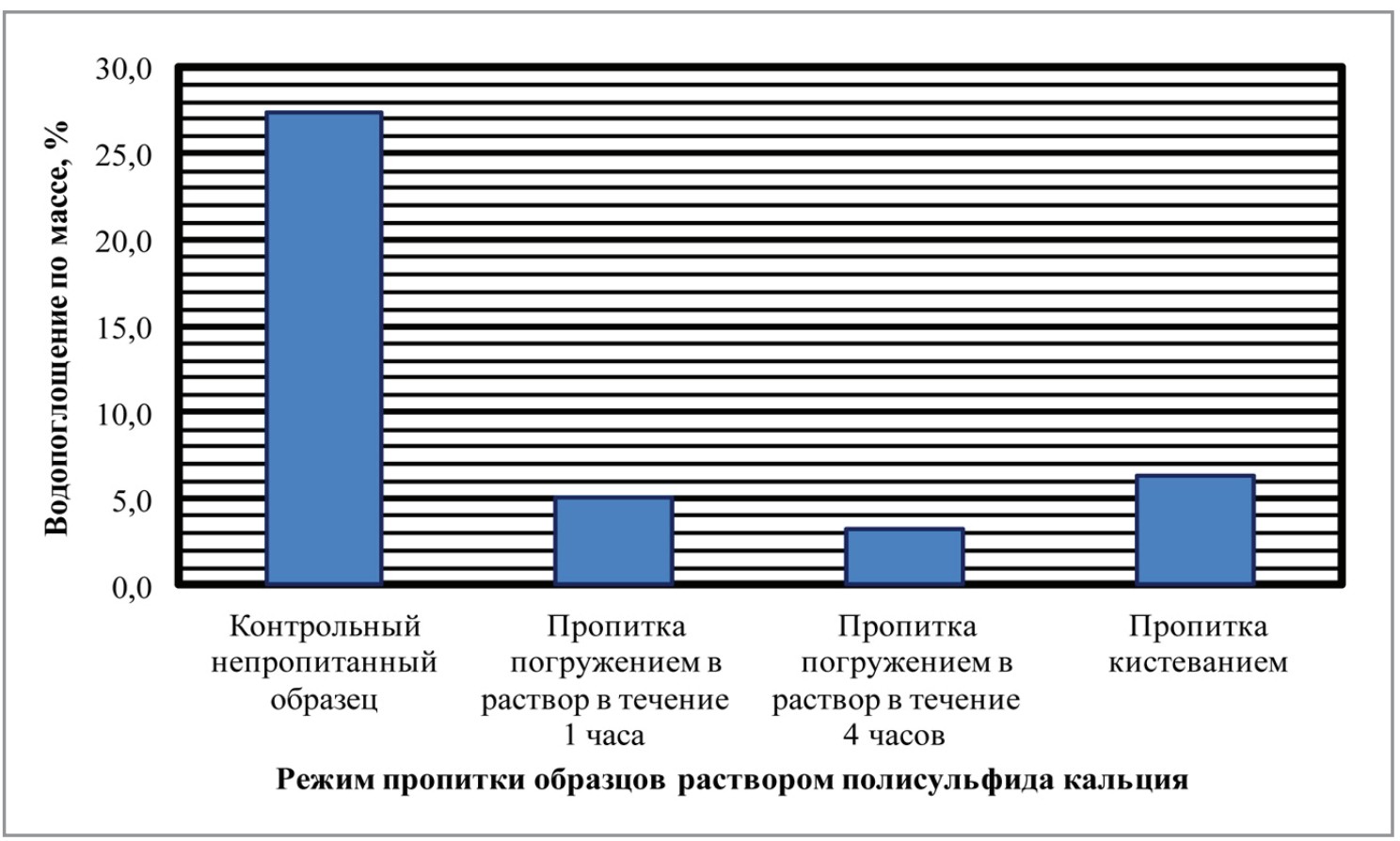

Рис. 4. Влияние режима пропитки полисульфидным раствором на водопоглощение по массе образцов известняка-ракушечника

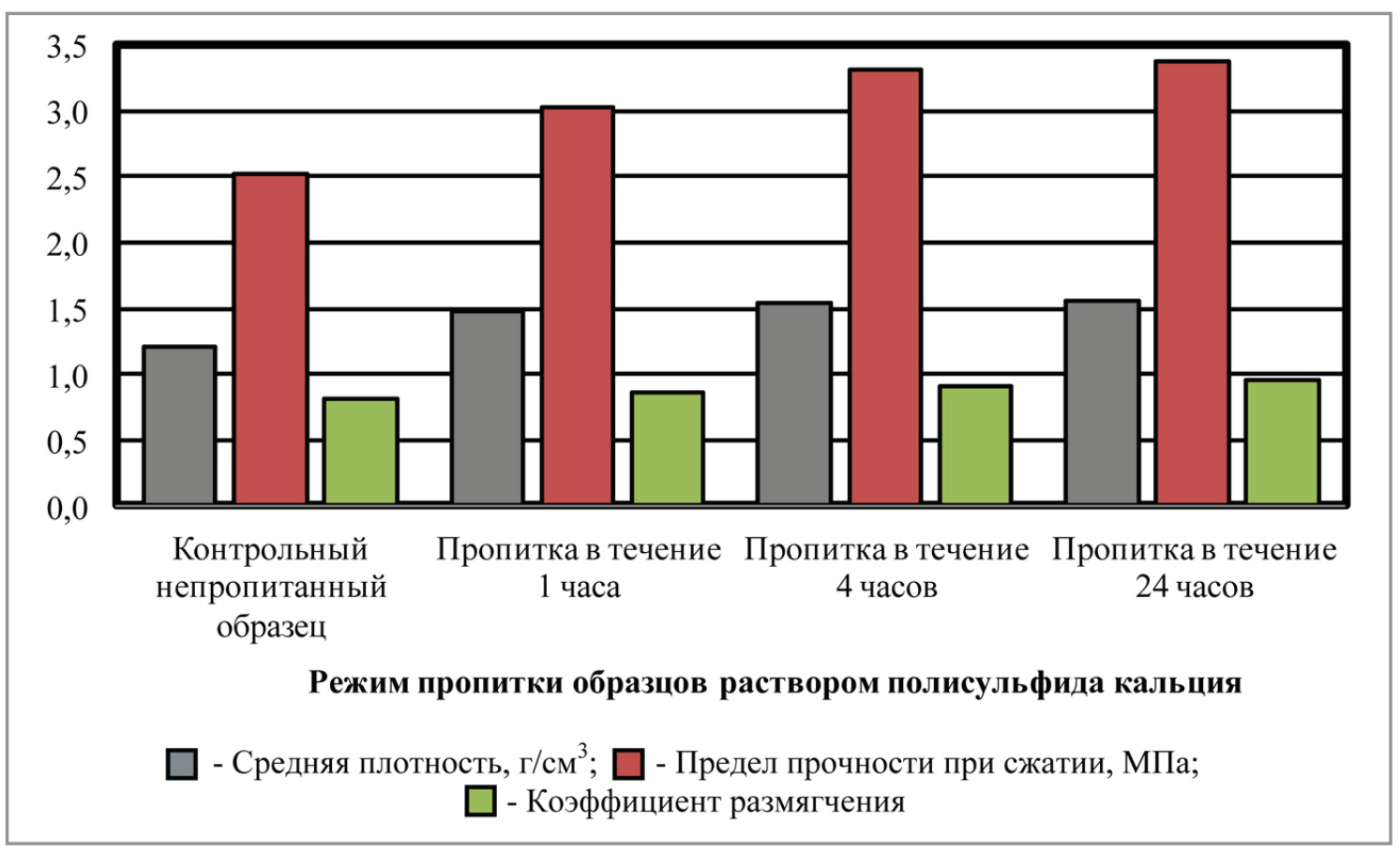

Рис. 5. Влияние режима пропитки полисульфидным раствором на среднюю плотность, прочность при сжатии и коэффициент размягчения образцов известняка-ракушечника 
Средняя плотность образцов, пропитанных в течение 1 часа, по сравнению с контрольными увеличилась на $22,4 \%$. Пропитка образцов в течение 4 и 24 часов увеличивает плотность материала на $26,9 \%$ и $27,8 \%$ соответственно, что показывает эффективность и достаточность четырехчасового режима пропитки известняка-ракушечника (рис. 5).

Увеличение плотности образцов вследствие частичного заполнения пор известняка-ракушечника твердой фазой, при осушении материала после пропитки полисульфидным раствором, обеспечивает прирост прочности при сжатии камня, пропитанного в течение 1 часа, в 1,2 раза при повышении коэффициента размягчения на $6,2 \%$ по сравнению с аналогичными характеристиками непропитанных образцов; четырех- и двадцатичетырехчасовая пропитка образцов обеспечивает более глубокое проникновение пропиточного состава в поровую структуру известняка-ракушечника и увеличивает его предел прочности при сжатии в 1,3 раза при повышении коэффициента размягчения на 12 и 19\% соответственно (рис. 5).

Таким образом, результаты исследований, приведенные на рис. 4 и 5, показывают, что пропитка известняка-ракушечника полисульфидными растворами позволяет улучшить эксплуатационные свойства и повысить долговечность стеновых, облицовочных и дорожных строительных материалов на его основе, подвергающихся атмосферным воздействиям, что позволит расширить традиционную область применения таких материалов - южные регионы России, климатические условия средней полосы России.

Работа поддержана ПЦФ Республики Казахстан и Российским фондом содействия развитию малых форм предприятий в научно-технической сфере CT APT-2015.

\section{Библиографический список:}

1. Дворкин Л.И. Строительное материаловедение / Л.И. Дворкин, О.Л. Дворкин. М.: Инфра - Инженерия, 2013. - 832 с.

2. Албариулян Н.В. Строительные горные породы для производства стеновых и облицовочных материалов. - М.: МГИ, 1982. - 282 с.

3. Селентовский Ю.В. Камни облицовочные: Справочник / Науч. ред. А.С. Филько; М-во природ. ресурсов РФ. - М.: Геоинформмарк, 1998. - 25 с. 
4. Селиентовский Ю.В. Известняк: Справочник / Науч. ред. А.С. Филько; М-во природ. ресурсов РФ. - М.: Геоинформмарк, 1999. - 19 с.

5. Горная энциклопедия / Гл. ред. Е.А. Козловский; Ред. кол.: М.И. Агошков, Н.К. Байбаков, А.С. Болдырев и др. - М.: Сов. энциклопедия, 1985. - Т. 2. - 575 с.

6. Бакка H.T. Облицовочный камень. Геолого-промышленная и технологическая оценка месторождений: Справочник / Н.Т. Бака, И.В. Ильченко. - М.: Недра, 1992. - $303 \mathrm{c}$.

7. Природные облицовочные камни Казахстана: справочник / Под ред. А.А. Абдуллина, Х.А. Беспаева, Э.С. Воцалевского, С.Ж . Даукеева, Л.А. Мирошниченко. Алматы: Информационно-аналитический центр геологии и минеральных ресурсов РК, 2000. - T. 1. - 181 с.

8. Чухланов В.Ю. Гидрофобизирующая жидкость для бетонных и железобетонных конструкций / В.Ю. Чухланов, А.Н. Алексеенко // Строительные материалы. 2003. - № 12. - С. 38-39.

9. Логанина В.И. Стойкость защитно-декоративных покрытий наружных стен зданий / В.И. Логанина, Л.П. Орентлихер. - М.: Издательство Ассоциация строительных вузов, 2000. - 104 с.

10. Рейблан А.И. Защитные лакокрасочные покрытия. - Л.: Химия, 1982. - 320 с.

11. Массалилов И.А., Волгушев А.Н., Чуйкин А.Е., Хусаинов А.Н., Мустафин А.Г. Долговременная защита строительных материалов покрытиями на основе наноразмерной серы // Нанотехнологии в строительстве. - 2010. - №1. - С. 45-58. URL: http://www.nanobuild.ru/ru_RU/journal/Nanobuild_1_2010_RUS.pdf (дата обращения 24.04.2017).

12. Янахлетов М.Р., Чуйкин А.Е., Массалилов И.А. Модифицирование поровой структуры цементных бетонов пропиткой серосодержащими растворами // Нанотехнологии в строительстве. - 2015. - Том 7, № 1. - C. 63-72. - URL: http://nanobuild. $\mathrm{ru} / \mathrm{ru}$ _RU/journal/Nanobuild-1-2015/63-72.pdf (дата обращения 24.04.2017).

13. Массалилов И.А., Янахлетов М.Р., Чуйкин А.Е. Прочность и долговечность бетона, модифицированного пропиточными составами на основе серы // Нанотехнологии в строительстве. - 2015. - Том 7, № 3. - C. 61-75. - URL: http://www.nanobuild. $\mathrm{ru} / \mathrm{en} \_\mathrm{EN} / \mathrm{journal} /$ Nanobuild-3-2015/61-75.pdf (дата обращения 24.04.2017).

14. Массалимов И.А., Мустафин А.Г., Чуйкин А.Е., Волгушев А.Н., Массалимов Б.И., Хусаинов А.Н. Упрочнение и увеличение водонепроницаемости бетона покрытиями на основе наноразмерной серы // Нанотехнологии в строительстве. - 2010. - № 2. - C. 54-61. - URL: http://www.nanobuild.ru/ru_RU/journal/ Nanobuild_2_2010_RUS.pdf (дата обращения 24.04.2017).

15. Massalimov I.A., Yanakhmetov M.R., Chuykin A.E., Mustafin A.G. Protection of Building Constructions with Sulfur Impregnating Solution. Study of Civil Engineering and Architecture (SCEA). June 2013. Vol. 2. Issue 2. pp. 19-24. 
16. Трансформация молекул полисульфидов в наноразмерные частицы серы в пористых неорганических системах / М.Р. Янахметов, И.А. Массалимов, А.Е. Чуйкин, А.Н. Хусаинов, А.Г. Мустафин // Вестник Башкирского Университета. - 2013. Т. 18, № 3. - С. 691-693.

17. Массалилов И.А., Бабков В.В., Мустафин А.Г. Состав для обработки строительных материалов и способ их обработки // Патент РФ № 2416589. С04B 41/45. / № 2009135548/03; заявл. 23.09.2009; опубл. 20.04.2011. Бюл. № 11. -6 с.

18. Массалилов И.А., Янахлетов Р.Р., Чуйкин А.Е., Хусаинов А.Н., Мустафин А.Г. Способ обработки строительных материалов полисульфидными растворами // Патент 024383 Евразийский, С04B 41/50. С04B 28/36 / № 201400277; заявл. 26.03.2014; опубл. 30.09.2016. Бюл. № 9. -5 c.

19. ГОСТ 9479-2011. Блоки из горных пород для производства облицовочных, архитектурно-строительных, мемориальных и других изделий. Технические условия.

20. ГОСТ 30629-2011. Материалы и изделия облицовочные из горных пород. Методы испытаний.

\section{УВАЖАЕМЫЕ КОЛЛЕГИ!}

ПРИ ИСПОЛЬЗОВАНИИ МАТЕРИАЛА ДАННОЙ СТАТЬИ

ПРОСИМ ДЕЛАТЬ БИБЛИОГРАФИЧЕСКУЮ ССЫЛКУ НА НЕЁ:

Массалилов И.А., Чуйкин А.Е., Массалилов Б.И., Уракаев Ф.Х., Уралбеков Б.М., Буркитбаев М.М. Улучшение эксплуатационных свойств строительных материалов из известняка-ракушечника пропиткой полисульфидными растворами // Нанотехнологии в строительстве. - 2017. - Том 9, № 3. - С. 6680. - DOI: dx.doi.org/10.15828/2075-8545-2017-9-3-66-80.

\section{DeAr COlleagues!}

THE REFERENCE TO THIS PAPER HAS THE FOLLOWING CITATION FORMAT:

Massalimov I.A., Chuykin A.E., Massalimov B.I., Urakaev F.H., Uralbekov B.M., Burkitbaev M.M.Improvement of operational properties of shell limestone building materials by polysulfide solution impregnation. Nanotehnologii v stroitel'stve = Nanotechnologies in Construction. 2017, Vol. 9, no. 3, pp. 66-80. DOI: dx.doi. org/10.15828/2075-8545-2017-9-3-66-80. (In Russian).

Контактная

инфорлация:
Массалимов Исмаил Александрович ismail_mass@mail.ru 